\title{
The Future Prospects of Taiwan's Non-Specialized Retail
}

\author{
Tso Chun-To ${ }^{1}$, Lee Tzong-Ru ${ }^{2}$, Yu Ching-Yun ${ }^{1,3,}{ }^{*}$, Wu Dai-Lun ${ }^{1}$, Su Yu-Ping ${ }^{1}$ \\ ${ }^{1}$ Research Division I, Taiwan Institute of Economic Research, Taipei City, Taiwan \\ ${ }^{2}$ Department of Marketing, National Chung Hsing University, Taichung City, Taiwan \\ ${ }^{3}$ Graduate Institute of Business Administration, Fu Jen Catholic University, New Taipei City, Taiwan
}

\section{Email address:}

d1948@tier.org.tw (Tso Chun-To), trlee@dragon.nchu.edu.tw (Lee Tzong-Ru),d20778@tier.org.tw (Yu Ching-Yun), d31464@tier.org.tw (Wu Dai-Lun),d32688@tier.org.tw (Su Yu-Ping)

${ }^{*}$ Corresponding author

\section{To cite this article:}

Tso Chun-To, Lee Tzong-Ru, Yu Ching-Yun, Wu Dai-Lun, Su Yu-Ping. The Future Prospects of Taiwan's Non-Specialized Retail. International Journal of Intelligent Information Systems. Vol. 6, No. 4, 2017, pp. 47-55. doi: 10.11648/j.ijiis.20170604.12

Received: September 21, 2017; Accepted: October 13, 2017; Published: November 16, 2017

\begin{abstract}
In the consumer-centric era, the intense competition forced retailers have to expand their product offering and deepen their services to satisfy consumers. In respond the customer demands, retailers have devoted in Omni-channel integration, Internet of Things (IoT) applications and supporting diversified payment tools. In aspect of Nonspecialized-Retailers' product offering, more and more horizontal alliances are formed in order to provide a one-stop service, in addition, many shopping centers and department stores in Taiwan invested in remodeling projects to attract international brand to station in.
\end{abstract}

Keywords: Retail, Omni-Channel, IoT

\section{Introduction}

Along with the spread of mobile devices the and evolution of mobile communication technologies, information transparency the developed infrastructure accelerated the growth in payment flow, logistics and information flow development, narrowed the time and geographic barrier, empowered consumers to have diversified options.

With the development of Information and Communications Technology (ICT), the new business model of online and offline channel integration has made innovation from the old. It probably includes four aspects: (1) Online to Mobile(O2M) based on mobile e-commerce-; (2) as opposed to Online to Offline, Offline to Online means that the customers in physical stores (Offline) would go shopping in online stores, it would become the idea of Omni-channel; (3) the customized of $\mathrm{O} 2 \mathrm{O}$ sales are developed by the use of big data analysis technology;(4) the $\mathrm{O} 2 \mathrm{O}$ digital sales are developed by the use of augmented reality(AR), radio frequency identification (RFID) and other technology in the physical access [1].

In developing Omni-channel, one of the most popular issues in recent years for the e-commerce is to construct a fast-delivery service mode in order to compete with the physical access. In Taiwan, the fast-delivery service is also utilized in the retail industry nowadays, and the purchasing patterns of the consumers are also changing in the upcoming years [2].

In the consumer-centric, price and quality are no longer the only considerations, but also some emotional perceptual like shopping experiences. In respond to the trend, retailers have to improve their competitiveness and customer satisfaction through applying new technologies and developing new business model.

According to Nielsen Global Electronics Business survey has investigated more than 30,000 Internet consumers in 63 markets around the world from October to November 2016. The result refers that $85 \%$ of Taiwanese respondents are willing to receive orders from the store after they have placed their orders online, as compared to the Asia Pacific consumers $(79 \%)$. In addition, online shopping with home delivery is the most popular retail shopping model in Taiwan and the Asia Pacific [3].

However, shopping is not just a matter of planning and functionality, but also the emotional needs of impulsive shopping and live experience. The ability of the physical 
store to be full of experience and emotion is precisely what can not be replaced by e-commerce [4]. Traditional distributors can build an e-commerce business model to marketing in order to meet the needs of more different customers, and to increase revenue [5].

Furthermore, the physical access combined with the smart retail solutions will provide the efficiency of business management, such as shop outsiders, customer analysis, intelligent electronic billboards, entry and exit counting applications and customer behavior analysis. In the analysis of customer behavior in the store, passenger flow detection function can provide customer shopping routes and flow analysis; shopping hot area detection function can provide customers in the hot area of the stay time and stay frequency analysis, so that the physical stores would be designed for the best traffic flow [6].

The study will firstly describe the state quo of Non-specialized retail industry in Taiwan, and then discuss the retail transformation trends in aspects of Omni-channel integration, Internet of Things (IoT) application and mobile payment, case study to analyze the success strategies of Pxmart and finally summarize the Non-specialized developing trends in Taiwan.

\section{Forward}

Retail industry contains a wide range of businesses, such as shopping center, department stores, supermarkets, hypermarkets, convenience stores, leisure clothing, bookstores, audio visual, drug stores, home appliances, daily groceries, digital technology, gas stations, food industry, catering, living services, entertainment, beauty salons, health and leisure, etc. Retail output also reflects a Nation's standard of living.

According to the basic principle of Taiwan Chain Store Almanac census, Taiwan's chain brands had been classified into four major formats, they are Non-specialized retail, Specialized retail, Catering and Living service. The research of 2016 Taiwan chain store almanac shows that Specialized retail accounted for $37.1 \%$ of headquarters of all Taiwan's chain store industry which is the most, and then followed by Catering (34.8\%), Living service (24.2\%) and Non-specialized retail $(3.9 \%)$. The figure shows that retail enterprises accounted for two-fifth of Taiwan's chain enterprise numbers that is a very important sector in the chain industry.

Non-specialized retail includes convenience stores, supermarkets, hypermarkets, shopping centers and department stores. There are clear segments among these five formats of business in terms of their business model, target audience, and product categories. The research of 2016 Taiwan Chain Store Almanac indicates that convenience store has the most number of stores, which accounted for 10,321 stores $(81.8 \%)$ of overall number of Non-specialized retail stores in Taiwan, and then followed by supermarket $(1,994$ stores $(15.8 \%))$ and hypermarket (154 stores $(1.2 \%))$, while department store (112 stores $(0.9 \%))$ and shopping center $(29$ stores $(0.2 \%))$ constituted for relatively lower share in 2015 .

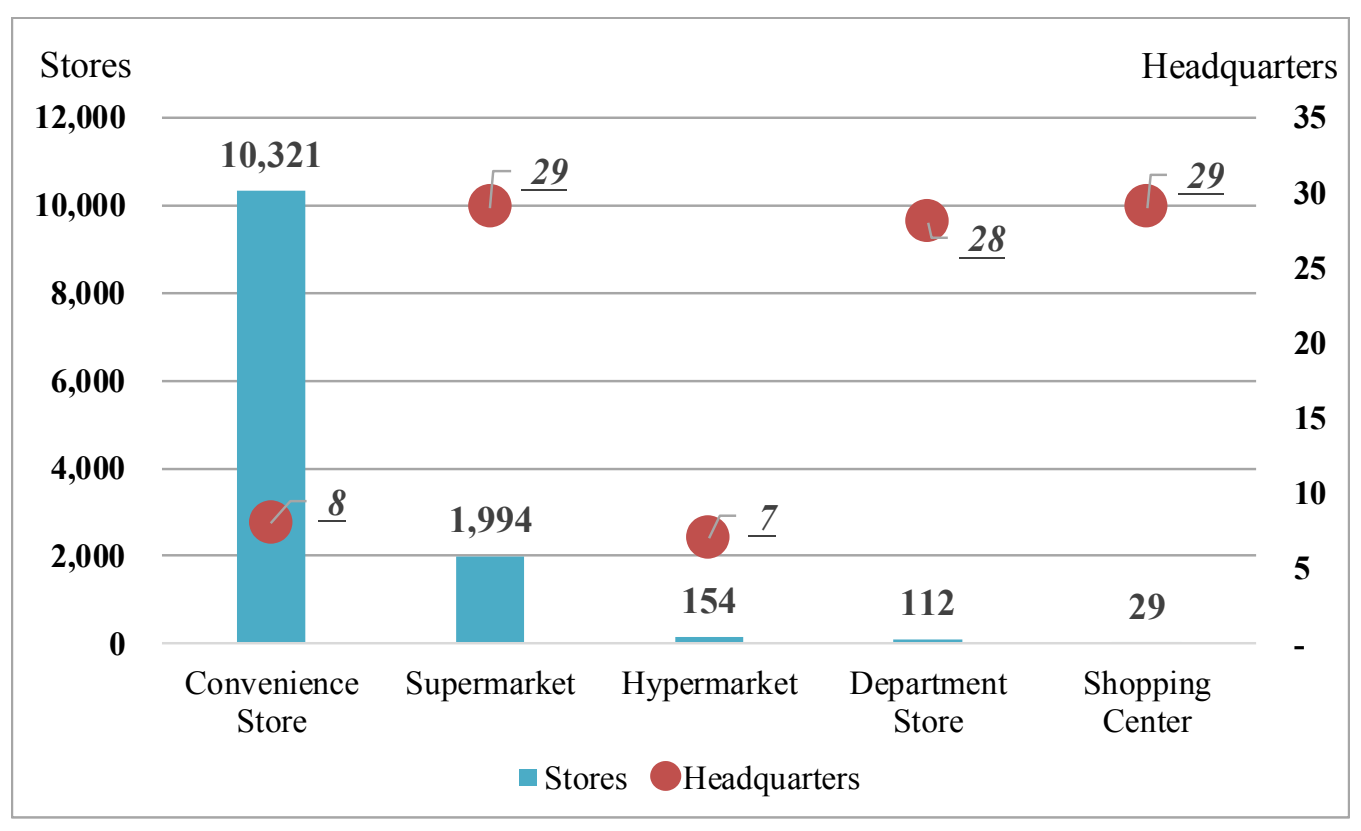

+Source: 2016 Taiwan chain store almanac.

Figure 1. The numbers of Non-specialized retail stores and headquarters in 2015.

According to the "Chain Industry Investigation 2015" conducted by Taiwan Institute of Economic Research (TIER), the results found that the expansion plan of these Non-specialized retailers, $41.8 \%$ of retailer plan to open new stores in Taiwan in 2016, however in 2015, there were merely $28.7 \%$ of responders has the domestic expansion plan. The shift can be attributed to the establishment of many new shopping centers. 


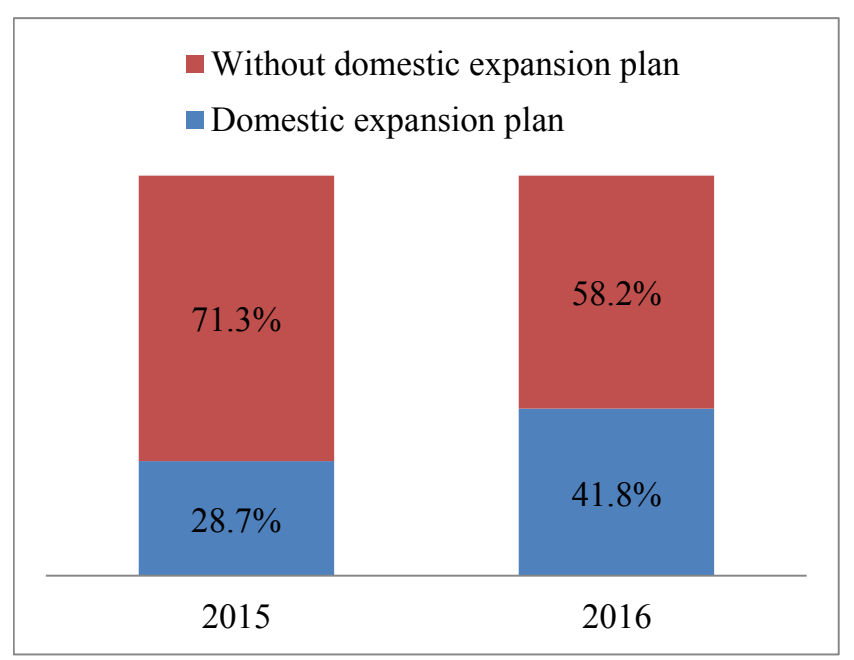

+Source: Chain Industry Investigation 2015. Redrawn from the study.

Figure 2. Domestic expansion plan of Non-specialized retailers in 2015 and 2016.

Non-specialized retailers generally have greater overseas investment. According to Chain Industry Investigation 2015, each Non-specialized retailers at least invest more than 50 million NTD oversea. All the responders planned to invest in China in 2016, while few of them are negotiating with their Southeast Asia investment.

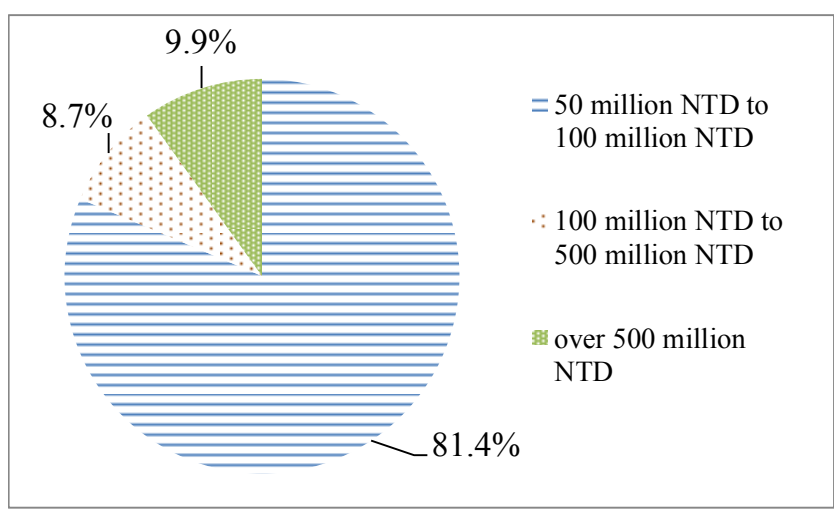

+Source: Chain Industry Investigation 2015. Redrawn from the study.

Figure 3. The planned oversea investment amount of Non-specialized retailers in 2015 .

Chain Industry Investigation 2015 exhibits the e-commerce involvement degree among different business formats. Generally, Non-specialized retailers showed a higher e-commerce adoption rate compared with the overall chain industry, $60.3 \%$ of them have run their FB fan groups, $54.3 \%$ have operated their own online shopping website and $48.6 \%$ have sold their product on other shopping platforms. Non-specialized retailer also exhibited a higher rate of $\mathrm{O} 2 \mathrm{O}$ business involvement than other business formats.

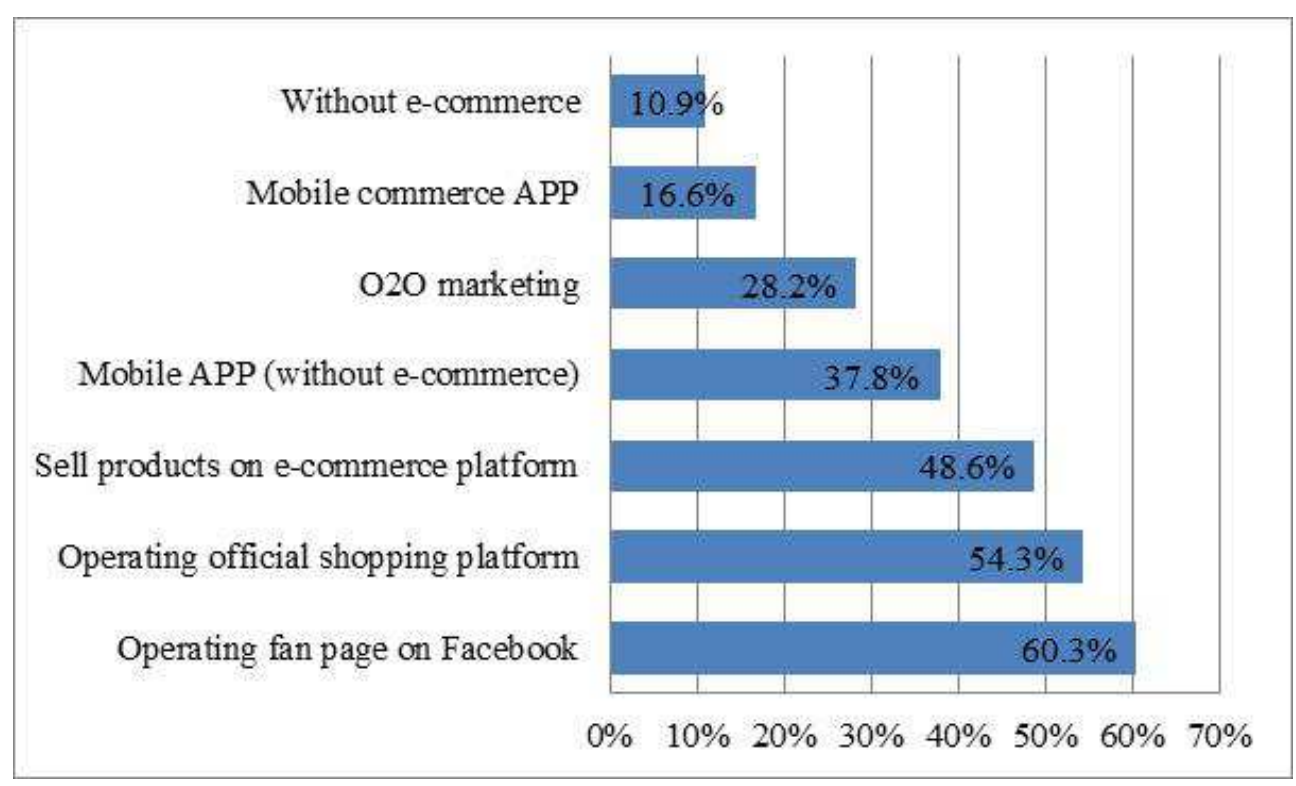

+Source: Chain Industry Investigation 2015. Redrawn from the study.

Figure 4. E-commerce application in chain industry.

During 2014 and 2015, the rise and fall in domestic demand is the most effective factor impact on the operating environment in Non-specialized retail industry, and the second effective factor is the plight of working hours and minimum wage adjustments, the figure aggravated significantly in 2015 . Apart from these factors, more and more respondents regard the rapid growing e-commerce is another considerable impact. In 2015 , more than $50 \%$ of respondents consider rapid growing e-commerce as an influential factor, however, the figure is merely $20 \%$ in 2014 . The survey also undertook in-depth interviews to support the finding, an interviewee stated "Some companies had established e-commerce 10 years ago, although there was a decrease in the numbers of the brick and mortar store visitors, however, the e-commerce business successfully filled the vacancy of the sales loss in brick and mortar stores to reduce the overall impact." The statement seems disclose that the chain industry had prepared for the business environment changing. 


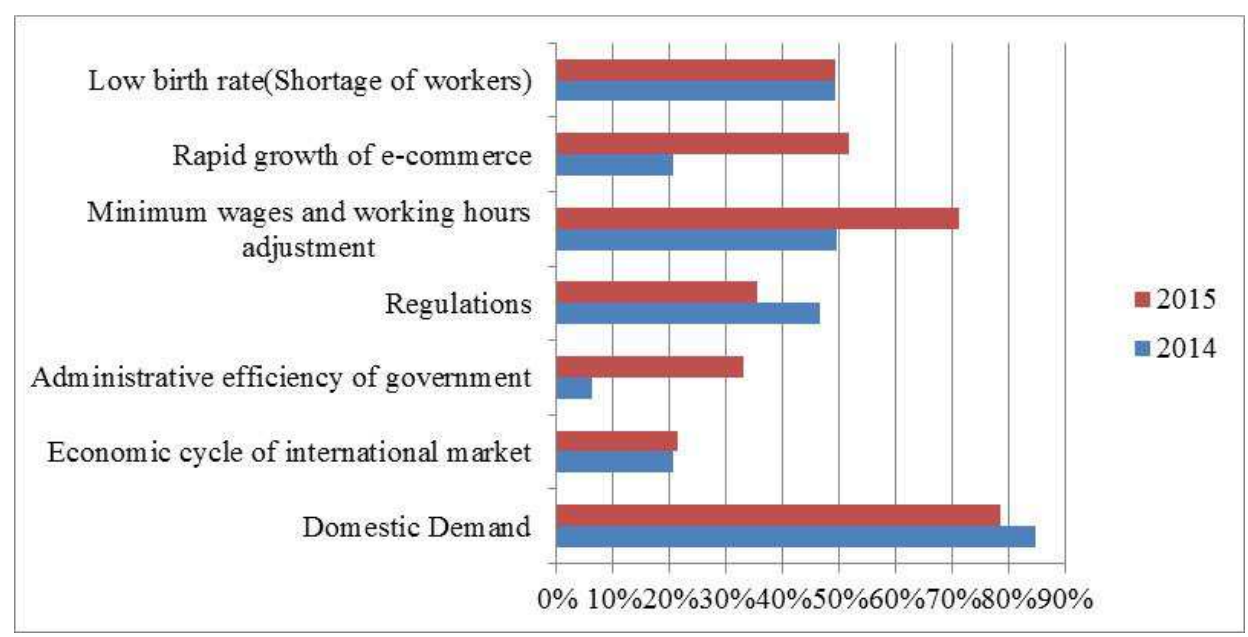

+Source: Chain Industry Investigation 2015. Redrawn from the study.

Figure 5. The plight of in chain industry.

Overviewing the current trend of Taiwan's Non-specialized retail industry, enterprises still keep their new stores opening and oversea expansion plan in the future. In addition, with the handheld devices evolution and mobile networks flourish, the gap between online and offline is narrowed. The retail channel trend is progressed form multi-channel toward Omni-channel. For consumers, the attraction of traditional marketing tools such as offer discounts or giveaway are limited, the future trends are likely to focus on consumer experience and innovative marketing models.

\section{Transformation Trends}

Technology products innovation has prompted the commercial activities changes in retail industry, including marketing technology application, food safety certification that in response to the rise of consumer protection awareness, logistics, payment system and so on. The innovation integrates production management, marketing activities, payment systems and logistics systems.

\subsection{Omni-Channel Thinking}

Omni-channel aims to eliminate the restrictions result from inventory, location, delivery time and other factors. With a mobile device, consumers are able to enjoy the shopping experience online, and retailers can plan new patterns of marketing activities in brick and mortar stores as well. As e-commerce experiencing an explosive growth, traditional retailers successively stepped into the market through running their own online shopping platforms or cooperating with other e-commerce operators. With online channel and physical stores, retailer started to integrate them in a multi-channel form. Multi-channel enables consumers to purchase both online and offline. Retailers also have to integrate their own multi-channel thereby offering a full-time service that contains sales services, promotions, payments, logistics and the after sales services. Without the barriers of time difference and geographic difference, all the consumers' needs are able to be satisfied form multi-channel integration, so called "Omni-channel".

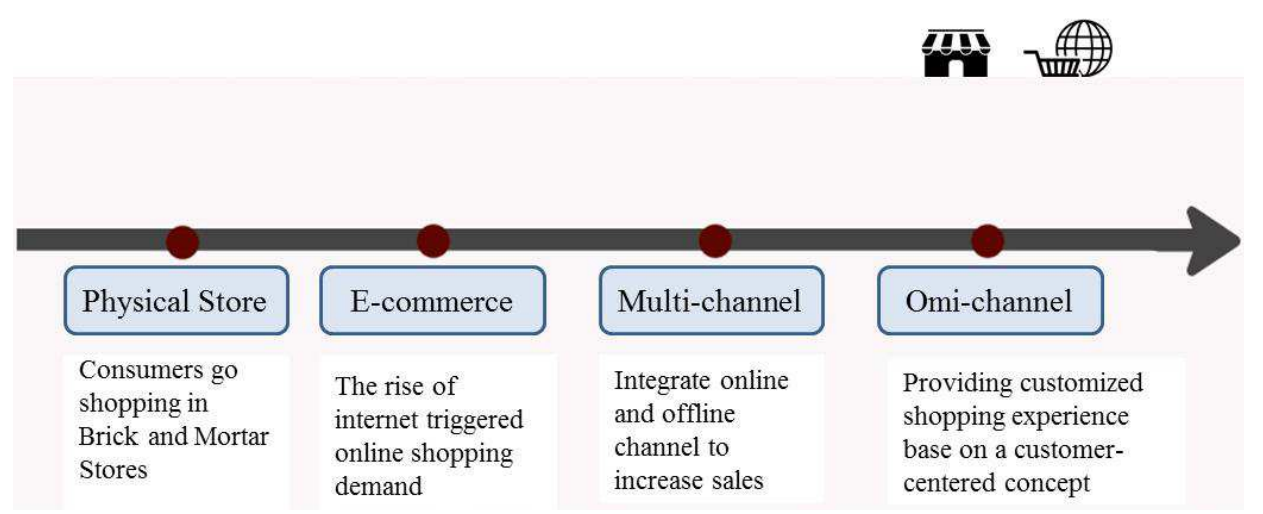

Figure 6. Retail channel evolution.

Providing diverse shopping options and a full-time shopping space are two key elements of Omni-channel. Under the Omni-channel structure, retailer's marketing plans are likely to be more flexible due to there is no shopping time limitation. All the data collecting devices enable retailer to analyze consumer behavior thereby planning more 
customized advertising messages.

\subsubsection{Online Channel}

In aspect of marketing activities, retailers continually use internet on branding, merchandising and promoting. Online advertising can be classified into proactive and passive. Search Engine Optimization (SEO) is one of the represented passive form, retailers' information will emerge when user search the key words. According to Global Powers of Retailing 2015 released by Deloitte, there are approximately 95\% of respondents regarded the Search Engine as their target market. Search Engine Advertising (SEA) is one another marketing tool together with search engine, the advertising will show up when users type the key words.

Contrary, the proactive advertising generally shows on the target-email or social media. Target-email and can use the current big data to acquire customer's information, and then send the most relevant or personalized message to the consumers. Social media is likely to be one the most popular marketing tool in recent years. Many marketing activities can be implemented through operating fan page on the social medias like Facebook, Instagram or Twitter, combine with in-store technology and promotion activities, social media is likely to be the first choice platform to link the physical and the virtual channels.

\subsubsection{Offline Channel}

In brick and mortar store, experience marketing is one of the key elements in retail operating. For consumers, merchandise prices in brick and mortar stores may not be as compatible as shopping online, however, some experiences in physical stores such as product trial, interactive product illustration tutorial and shopping conversation with stuffs are irreplaceable, thus, price is no longer the only consideration for consumers.

In order to deepen customer interaction, retailers embraced some new techs, for example, an interactive virtual mirror, a new tech apply augmented reality (AR) that allows shoppers virtually try on various clothes and accessories through a digital signage. Or, like Hugo Boss, use interactive advertising flyers, and allow consumer to take pictures and playing games on electronic billboard to create interactive experiences.

Retailers aim to acquire consumers' in-store collecting and trialing behavior to analyze the future trends. Combining Beacon and mobile App not only can deliver the sales discounts and the adverting information to customer who is approaching the store, but also collect in-store behavior data such as the path maps and dwell time, enable retailers to analyze customer behavior thereby optimize the placement and line planning. In addition, Retailers are able to adjust their online and offline marketing strategies according to the consumer behavior finding, and thereby achieving Omni-channel mode.

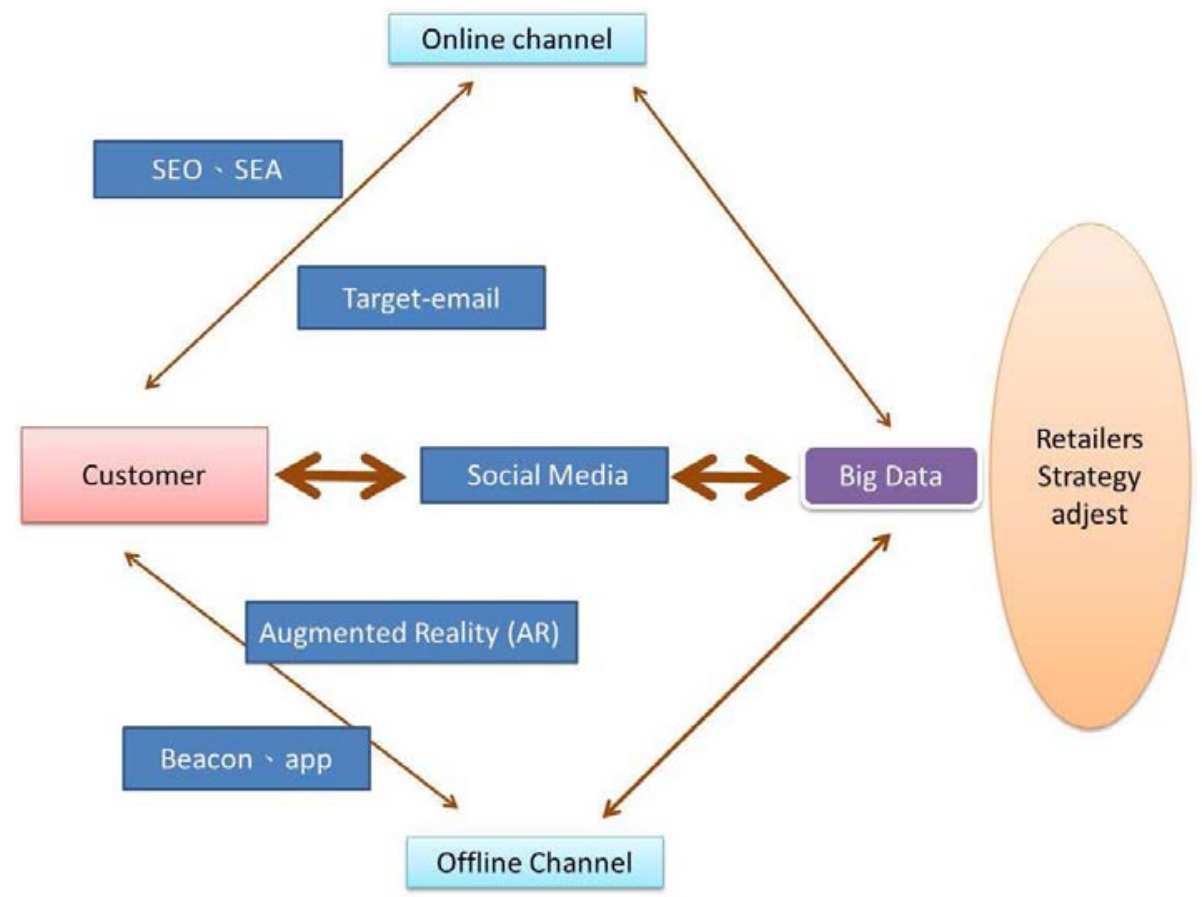

Figure 7. Online and offline channel integration.

\subsection{IoT Apply on Smart Retail}

In Omni-channel Era, IoT is one of the most important technologies applied on information sharing and decision-making. Few years ago, most of Taiwanese companies' IT infrastructure still stayed at an elementary stage, merely use to maintain the internal management and basic operations. In the past, IoT mainly used in collecting data by sensing; nowadays, IoT technologies are able to generate new data through analysis. The tech can be applied on transportation, health care, retail, logistics, industrial 
production, environmental monitoring and other industries. In retail logistics, IoT can help retailer building traceability system or establishing the optimized supply chain value.

\subsubsection{Supply-Side (Food Traceability)}

In recent years, food safety is a great concerned issue in Taiwan's retail industry. In response to the issue, Taiwan's government also introduced traceability cloud application on food safety. Technically, technologies such as Radio Frequency Identification (RFID) and the International Barcode are able to help retailers implementing food traceability management. The IoT information transmission network can apply on food production and marketing process optimization. The sensors on food packages can be used in tracking food expiration dates and other relevant information to achieve traceability management and improve the decision-making accuracy.

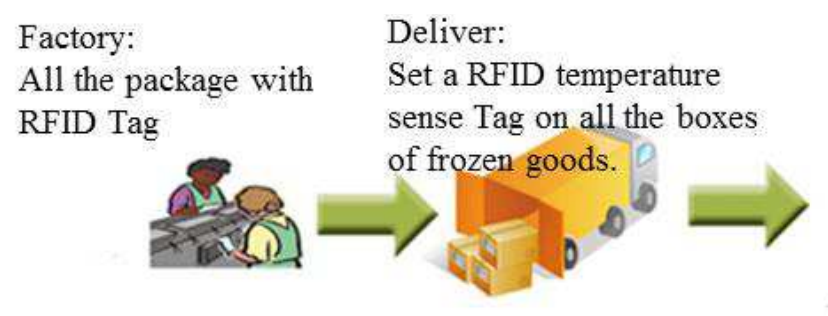

Case 1: Hsin Tung Yang

Hsin Tung Yang, a Taiwanese food service company and retailer, in line with the "History Traceability Project for Packaged Food" implemented by Department of Commerce, Ministry of Economic Affairs, R.O.C., Hsin Tung Yang used 2D bar code to record livestock farm names, the dates and other information of slaughterhouse. In order to extend the traceability from production to all the distribution processes, the company established the traceability system with Industrial Technology Research Institute, used RFID technology to record the whole food supply process, from production, logistics, distribution, store until sales. Consumers are able to trace all the process through KIOSK scanning machine in Hsin Tung Yang stores to view the transparent information [7].

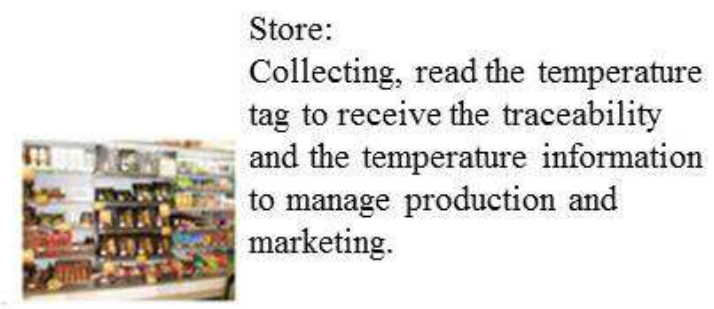

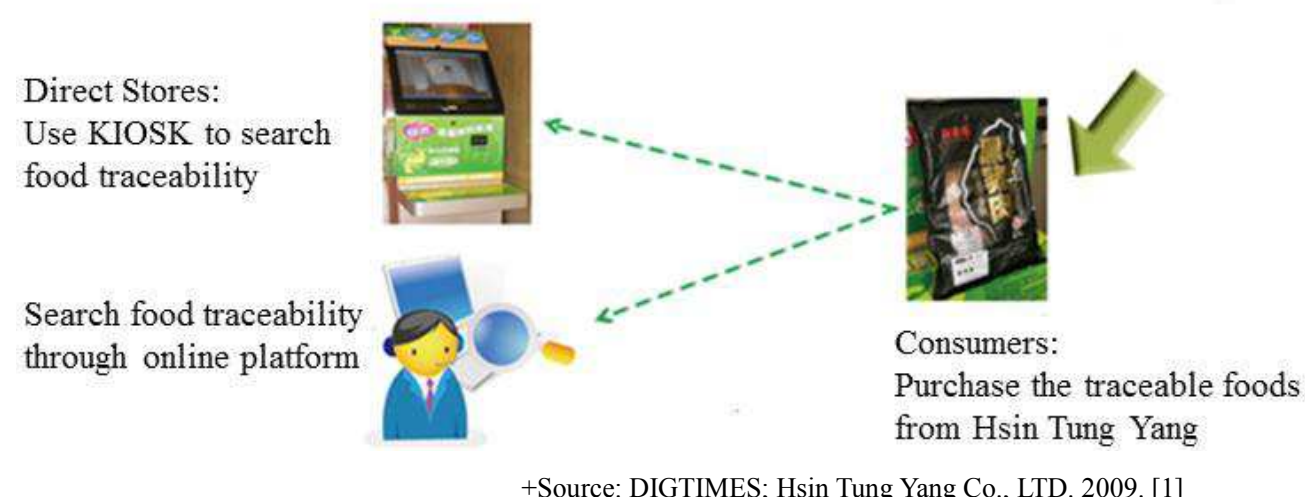

Figure 8. Hsin Tung Yang packaged food traceability operating process.

\subsubsection{Logistics}

In aspect of inventory management, enterprises can apply IoT technologies to collect the supply chains and sales side information, the collected information will be transmitted to the central computer to for real time inventory management. Combine with automation technology, IoT can handle multiple tasks for enterprises. In addition, logistics providers also use RFID technology to manage their merchandises and route, apply on delivery planning, progress tracking, and improving accuracy. Extended to the shop, IoT can also be used in regional guidance. Appling basic parking guidance technology can help consumers to save the time that spend on looking for a parking space.

Case 2: Retail Support International

Retail Support International is a logistic company owned by Uni-President Enterprises Corporation. The company applies RFID technologies to manage the size and weight of the ordered merchandise, plan delivery route and control the real-time arrival information. During the purchase, collecting and delivery process, the label on box and pallets can help logistics operators to identify the ordered goods and the delivery goods thereby effectively reduce the risk of errors.

Case 3: Carrefour

Carrefour's logistic heavily relies on its advanced computer control system. The functions of the system contain order management, automatic replenishment, receiving, refund, change prices, shop-to-shop transfer, department-to-department transfer, inventory adjustments, inventory queries and reports. The computer also provides corresponding analysis to link the query and reporting functions.

Case 4: Syntrend Creative Park

Smart parking solutions integrate license plate recognition, vehicle guidance and car-searching system. It can guide 
visitors to find a parking space when they entering and make drivers to find out their cars easily when they leaving. In Taiwan, the represented parking lot applying the technologies is the one in Hon-Hai's Syntrend Creative Park [8]. When the vehicle enters the parking lot, the entrance display screen will show the dynamic real-time display of the position and the direction of the target parking spaces, and then guide visitors to the arranged parking space through an arrow image. If the guest fail to park at the arranged parking space, the system will correct it automatically. This application is usually combine with eTag, RFID and QR Code technologies, or even face recognition, provide multiple authentications to achieve automotive identity recognition to achieve advanced car park management and improve customer convenience [9].

\subsubsection{The Consumer Side}

Retailer can use IoT device to record customers' in-store behavior and collect big data. Through systematic big data analysis, the results can be used in product mix and placement optimization, and thereby enhance the promotion and recommendation accuracy to increase revenue.

Case 5: Family Mart

Family Mart had installed six cameras and the eye detection technologies in their new stores to record customers' path map and the dwell time in each region in the store. The collected data will be analyzed by system integrators to figure out the "bundle buy" behavior relationship (means consumers usually buy something together), and then adjust the merchandising placement accordingly to accelerate merchandise turnover. Product mix in convenience stores change frequently, introducing big data can help convenience stores to optimize its product mix to satisfy most of the consumers. Family Mart also decide to support diversified payment instruments, sharing customer information with payment platform to acquire much more customers' information and therefore estimate the demand, or even create the demand [10].

\subsection{Payment}

Mobile payment ecosystem contains Over - the - Air Technology (OTA) mobile handheld devices and contactless transaction devices. Near Field Communication (NFC) technology is currently the mainstream payment intermedium, the derived formats including Trusted Service Manager (TSM) and Android's Hosted Card Emulation (HCE).

The difference between the two forms is that TSM only work when inserting secure element, however HCE can simulate the wafer that TSM needs in the cloud to simplify the cooperation between payment industry and mobile industry. In addition, the Token code that applied on apple pay as a protective mechanism is another payment solution. Telecom operators, distributors and financial institutions all eager to step into the mobile payment market, however due to (1) the traditional financial services in Taiwan are sound that reduces consumers' motivation to shift to electronic payments [11]. (2) Payment tools in Taiwan are diversified, including cash, Easy Card, iPASS and other payment tools that released by retailers such as icash, Happy cash and so on [11]. (3) There are still many legal restrictions on electronic payments in Taiwan, such as a payment system can only transact when the buyer and the seller are both the member of this electronic payment system, the virtual account can only deposit by cash and so on [12]. These reasons all cause mobile payment development in Taiwan still remand in a preliminary stage. Horizontal integration by financial institutions and retailers is the most common form of mobile payment development in Taiwan, unlike many other countries that have more e-commerce or social media companies involved in the business. PChome's Pi mobile wallet and Macro Well OMG's allPay are two representative electronic payment systems successfully accessed Taiwan's retail industry [13].

Table 1. The mobile payment comparison in Taiwan's convenience stores

\begin{tabular}{|c|c|c|c|c|}
\hline $\begin{array}{l}\text { Mobile Payment } \\
\text { System }\end{array}$ & $\begin{array}{l}\text { The Supportive } \\
\text { Retailer }\end{array}$ & $\begin{array}{l}\text { The Binding Credit Card } \\
\text { Issuing Banks }\end{array}$ & Service & $\begin{array}{l}\text { The Maximum Payment } \\
\text { Amount }\end{array}$ \\
\hline Pi mobile wallet & 7-Eleven & CTBC Bank & $\begin{array}{l}\text { Only provide the binding credit cards collections } \\
\text { and payment transfer service currently. Governed } \\
\text { by Department of Commerce, Ministry of } \\
\text { Economic Affairs, R.O.C. }\end{array}$ & $\begin{array}{l}\text { The single transaction } \\
\text { limitation is } 1,000 \text { NTD. } \\
\text { No daily or monthly } \\
\text { payment limitation. }\end{array}$ \\
\hline allPay & $\begin{array}{l}\text { Family Mart, } \\
\text { Hi-Life }\end{array}$ & $\begin{array}{l}\text { Bank Sino Pac, Taishin } \\
\text { International Bank, E. Sun } \\
\text { Bank, KGIB, Shin Kong } \\
\text { Bank and Far Eastern } \\
\text { International Bank }\end{array}$ & $\begin{array}{l}\text { Owned by the electronic payment institution and } \\
\text { governed by FSC. Provide collections and } \\
\text { payment transfer service. Available for value } \\
\text { storage and P2P transfer. }\end{array}$ & $\begin{array}{l}\text { For general memberships, } \\
\text { the monthly payment } \\
\text { limitation is } 30,000 \text { NTD }\end{array}$ \\
\hline
\end{tabular}

\subsection{The Boundary Line of Different Format Pf Shop Are Blurred}

Due to the scale limitation and the intensified completion in Taiwan's mobile payment market, inter-industry horizontal cooperation is very common, particularly the cross-industry combination of convenience stores and other retailers. The cooperation modes can be classified into "Service Innovation Cooperation" and "Product Innovation Cooperation".

\subsubsection{Service Innovation Cooperation Example}

Family Mart, a Taiwanese 24-hours convenience store, cooperate with Great Tree Pharmacy, a franchise drugstore, take advantage of Family Mart's convenience, with pharmacists resident in store to provide consultancy service all day to satisfied patients' needs. Another one case is that Gogoro sets charging station in 7-Eleven stores to increase consumers' dwell time. 


\subsubsection{Product Innovation Cooperation Example}

TANHOU, a fresh food supplier, provide organic food and build a safe and transparent supply chain management mechanism for Family Mart to attract food safety conscious consumers. 7-Eleven worked with Starbucks to develop products. Nowadays, MUJI also set up counter in 7-Eleven to enable consumer purchase its product more conveniently.

From the two previously mentioned cooperate forms, it can be found that the earlier horizontal alliances forms mainly focus on product line expansion due to the store space limitation. The newer remodeled stores are generally brighter and more spacious that enable partners to set up multi-brand counters in the stores, equipped with sitting area and move toward multifunctional development.

\section{Domestic Retail Innovation Case-Pxmart}

Taiwan is a densely populated, commercialized country with a busy paced of modern life, thus convenience is highly regarded by Taiwanese people. The convenience stores, supermarkets and hypermarket all devote in offering a wide range of products and diversified services and attempt to snatch the business from others. Hypermarket and supermarkets gradually develop community-based small shop like the format of convenience stores, while convenience stores are serving some products that consumers usually purchase from supermarket such as fresh fruits, vegetables, frozen meat, etc. The competition among different kinds of grocery stores is increasingly fierce.

Pxmart was founded in October 1998, set reasonable price and safe quality as its selling point, successfully gained market share and had become the leading supermarket in Taiwan. Pxmart's currently run more than 800 stores. Its annual revenue reached NTD \$ 76 billion in 2014. Pxmart continually applies new technologies, introduces IBM's consulting service and technical support to upgrade its IT infrastructure. Moreover, Pxmart continually devotes in diversified and customize services offering, food safety, and developing localized agriculture.

\subsection{Cost Control-the Consignment Mode}

Competitive price and safety quality is Pxmart's brand image and core competitive advantage for its expansion. Before the business format transformation in recent years, dry goods were Pxmart's major commodities. Unlike fresh foods typically have shorter shelf lives, dry goods can be stored longer and more suitable for consignment. Under the consignment model, for suppliers, selling their products in Pxmart can save slotting fees and increase their sales via numerous Pxmart stores; for Pxmart, the cost of goods are allowed to be paid monthly after the goods sold, in addition, the ordering cost and inventory cost are also saved. The saved cost all reflect on its cheaper selling prices. In line with cost leadership strategies, Pxmart eliminating the cost of decoration, credit card service, beautiful uniforms, using "ordinary people" in ads to save marketing budget and operating in an efficient way to reduce rental cost and stuff cost. All these cost leadership strategies enable Pxmart to offer a $10 \%$ to $15 \%$ lower commodity prices than hypermarket, compare with the price level of convenience stores, it is about $20 \%$ to $30 \%$ cheaper [14].

\subsection{Local Specialties and Traceable Products}

With rising food security awareness and local farm products gradually favored by consumers, Pxmart launched its new patterns second-generation shop in 2014 with "direct procumbent from farmers" counters to enable small farmers selling on consignment and pricing by themselves. The mode merely charge a small number of overhead, promotion the agricultural goods by "direct deliver from the place of origin" and assist local farmers to establish their producing traceability and the cloud traceability platform to enhance public trust in the ingredients.

Pxmart's second-generation shop launched from Yunlin, Chiayi and Tainan where are the major agriculture region in Taiwan, with sitting area and semi-open kitchen in store to serve hot food, provide similar services as a convenient store, and the fresh foods proportion had raised to $50 \%$ [15].

\subsection{Improve IT Infrastructure to Deepen Service}

In order to expand their product line and service, Pxmart introduce the techniques and consultancy services from IBM to upgrade their IT infrastructure. Together with social media data, mobile data, big data analytics and cloud computing to improve supply chain efficiency, real-time delivery, and reduced inventory levels. Pxmart had accumulated more than 7.5 million members who contributed over $80 \%$ percent of the company's sales. Pxmart had collected a lot of data from its members, and the data analysis benefits to consumer behavior prediction that enable Pxmart to provide more customized services for its customer. In addition, Pxmart also plan to improve its personalized recommendations and provides delivery services in the future [16].

\section{Conclusion}

The major transformation strategies in Taiwan's Non-specialized retail in recent year include retail shop reconstruction, cross-industry cooperation, etc. In response to the Omni-channel trends, retailers successively introduce technology applications to integrate their online and offline channel and apply big data to analyze consumer behaviors. In addition, logistics system, traceable systems and commodities positioning systems constituted a smart retail concept to prop up the essence of Omni-channel. Apart from the commodity flow, the money flow evolution is another key point of Non-specialized retail (in convenience stores and supermarkets) layout in the future.

\subsection{Sustainable Innovation in Product and Service}

Products and Services are the core value of 
Non-specialized retail. In a small or medium sized retail store such convenience store or supermarket, the range of product category are confined by their limited shelf space. Under the intense competition, retailers' product mix should include some exclusive agent products apart from the evergreen products. In addition, combine with some marketing plan like redeeming bonus points or coupon collecting also can boost the volume of sales per customer. Retailers in Taiwan normally run long opening hours to satisfy the domestic consumers' needs and set special counters or shops-in shop through cross-industry alliance to make consumers feel more convenient to obtain what they want.

\subsection{Integrated Shopping Mall Create New Prospect}

In recent years, many retailers introduced famous international brands and exclusive licensed brands to attract customers. However, attracting famous international brands to enter their shop have to provide spacious exhibition space with a stylish decor, that caused many Taiwanese retailers embark on remodeling projects or shift their business model to become a themed shopping mall to make them different to any traditional department store. As Taiwan's public transportation infrastructure gradually completed, many large outlet offer some luxury brands commodities in reasonable prices makes Taiwanese consumers fascinated. In these new patterns of shopping centers or department stores, the latest retail technologies are applied to guide the consumers, create interactive opportunity, provide joyful shopping experiences and improve the shopping efficiency.

\section{References}

[1] Liu, L. H., "Omni-channel concept leads the new business era," Trade Magazine, 2015, no. 286, pp. 8-11.

[2] Shen, H. M., "An exploratory study of ecommerce Omni-channel global business trends," master's thesis of National Dong Hwa University, 2016.

[3] The Nielsen Company, "Nelson: Consumers go shopping with the integration of online and offline channel, and Omni-channel strategy helps retailers expand business opportunities," News center, 2017.

http://www.nielsen.com/tw/zh/press-room/2017/nielsen-report -omni-channel-strategy-driving-growth-as-consumers-embrac e-both-online-and-offline-channels.html.

[4] Yang, R. J., "The thinking of Retail and Omni-channel in the future (Part 1)," Big Data Group, 2017. http://group.dailyview.tw/2017/04/21/\%E6\%9C\%AA\%E4\%B E\%86\%Е9\%9B\%B6\%Е5\%94\%AE\%Е8\%88\%87\%Е5\%85\%
A $8 \%$ E9\%80\%9A $\%$ E8\%B7\%AF\%E6\%80\%9D\%E7\%B6\%A D\%EF\%BC\%88\%E4\%B8\%8A\%EF\%BC\%89/.

[5] Lee, H. L., "Discuss innovative business model of food marketing channel," master's thesis of Fu Jen Catholic University, 2017.

[6] Wu, Y. S., Qiu, Y. L., and Liu, H. S., "Customer Analysis Technology for Smart Retail Solutions," C. I. E. E Magazine, 2016. 4. 06, pp. 57-65.

[7] Lai, L. C., "Food safety is visible, HSIN TUNG YANG established the traceability system of the packaged foods," DIGITIMES, 2009.

http://www.digitimes.com.tw/tw/dt/n/shwnws.asp?CnlID=13 $\& \mathrm{Cat}=500 \&$ Cat $1=\& \mathrm{id}=147426 \#$ ixzz41eBHC $3 \mathrm{eV}$.

[8] Small Y, "Hon-Hai Akihabarasmart parking lot, finding parking spaces automatically with the face recognition and plate recognition in Syntrend creative park Taipei," PCDIY, 2014. http://www.pcdiy.com.tw/detail/776.

[9] Advantech, "Advantech smart parking solutions," 2013. http://www2.advantech.com.tw/catalogs/pdf/2013/201310210 859iParking_DM_FA.pdf.

[10] Chen, J. Y., "Interview with Yeh, Jung-Ting, big data assist the future stores of Family Mart," 2016. http://udndata.com/ndapp/udntag/finance/Article?origid=8289 975\&ptname $=\% \mathrm{E} 8 \% \mathrm{~A} 9 \% 95 \% \mathrm{E} 4 \% \mathrm{BC} \% \mathrm{~B} 0$.

[11] Lu, P. H., "Mobile payment eventually acted," Common Wealth Magazine, 2015, no. 587.

[12] Kang, W. R., "The first year of mobile payment, no one dare to open," chinatimes, 2016.

http://www.chinatimes.com/realtimenews/20160104000010-2 60412.

[13] Gan, W. J., "all Pay mobile payment launched in Family-Mart and Hi-life," NOW news, 2016.

https://tw.news.yahoo.com/\%E6\%AD\%90\%E4\%BB\%98\%E5 \%AF\%B6\%Е8\%A1\%8C\%E5\%8B\%95\%Е6\%94\%AF\%E4\% BB\%98-\%Е5\%85\%A8\%E5\%AE\%B6\%E8\%90\%8A\%Е7\%88 $\% \mathrm{BE} \% \mathrm{E} 5 \% \mathrm{AF} \% 8 \mathrm{C} \% \mathrm{E} 6 \% \mathrm{AD} \% \mathrm{A3} \% \mathrm{E} \% \mathrm{BC} \% 8 \mathrm{~F} \% \mathrm{E} 5 \% 95 \%$ 9F\%E7\%94\%A8-133514981.html.

[14] Sie, G. F., Ciou, J. R., and Yan, Y. N., "Operating strategies analysis of the chain supermarkets in Taiwan-in case of Pxmart," Management Information Computing, 2013, vol. 2, no. 2, pp. 46-67.

[15] Jhang, J. L., "Pxmart's second generation shop will set sales platform for small farmers," MANAGER, 2014. $\mathrm{http}: / / w w w . m a n a g e r t o d a y . c o m . t w / a r t i c l e s / v i e w / 42293$.

[16] Dai, T. F., "Pxmart aims to beat the top supermarket with the hundred billion revenue through IT, the future blueprint of IT framework is released," iThome, 2014. http://www.ithome.com.tw/news/87685. 